\title{
Should doctors be budget holders?
}

\author{
J R BARTLETT，G NEIL-DWYER，C C PENNEY， G HARWOOD
}

There are formidable obstacles to the efficient use of resources in the NHS and few incentives to use the service efficiently. Clinicians lack the time and technical skill to assess the cost implications of their decisions and accountants are helpless without access to the judgment of practising clinicians who understand what is happening to the patients. Even so, it is proposed to make more doctors accountable for the expenditure generated by their decisions in the hope that this will lead to a better use of resources. Doctors, it is argued, should become budget holders-that is, they should know what they spend and on what. But the amount that they can spend should also be limited. It seems to us that those who advocate and accept budgets have little or no idea of the factors that determine the real cost of treating patients.

\begin{abstract}
Method
The objective must first be defined and then the resources required to achieve it can be listed and costed. Anyone who has worked in several neurosurgical units will know that practices vary enormously from one department to another. For example, the part the unit plays in the care of injured patients varies from a total commitment, selective admission and consultation, to virtually none at all. There are other specialist services (for example, pain clinics, psychosurgery, stereotactic treatment for movement disorders, and so on) to which the commitment varies between units. The importance of the differences lies in the fact that they exist. The unfettered application of conclusions drawn from averages (norms) without taking into account variations in clinical practice is likely to damage the service. The local factors which determine the pattern of care offered by differing departments must also be considered. Even so, it is reasonable to compare resources used by a unit with the national average provision and to examine the reasons for any differences. An analysis along these lines might show ways of improving the use of resources.
\end{abstract}

\section{OBJECTIVES AND RESOURCES}

We believe that a department of neurology and neurosurgery should provide a comprehensive specialist service, available 24 hours a day throughout the year for anyone in need. This does not automatically imply that the care of all patients with head injuries or of the chronically and terminally ill is necessarily the work of a specialist department. Indeed, there are sound medical, social, and economic reasons why this should not be so. The regional service of the South-east Thames Regional Health Authority is used as an example.

The resources required include medical, nursing, and paramedical staff; special equipment and buildings; laboratory support and pharmacy services; "hotel" facilities (catering, laundry, cleaning); administration; and opportunities for teaching and research.

Most patients require resources which are particularly costly and difficult to duplicate. These must be identified because they determine the size, structure, and organisation of a unit that is economically and clinically efficient. The important factors for neurology and neurosurgery are the specialist staff and the high-technology equipment.

Brook General Hospital, Shooters Hill Road, Woolwich, London SE18 4LW

J R BARTLETT, MB, FRCS, consultant neurosurgeon G NEIL-DWYER, MB, FRCS, consultant neurosurgeon C C PENNEY, MB, FRCR, consultant neuroradiologist G HARWOOD, MB, MRCP, consultant neurologist

\section{STAFF AND EQUIPMENT}

Table I lists the key members of the medical team and the number necessary to produce the 24 -hour service correlated with the population served. This arangement implies a 1 -in-3 on call for the neurosurgeons, and a 1 -in-2 for the neuroradiologists and neuroanaesthetists. The neuropathologist is called occasionally for an emergency case. Assuming that the total number of neurosurgeons and neurologists in the United Kingdom is about right, we calculate that this team should serve a population of about $1.8 \mathrm{~m}$.

TABLE I-Key members of medical team*

\begin{tabular}{lcc}
\hline Key staff & $\begin{array}{c}\text { Population } \\
\text { served (million) }\end{array}$ & Method of estimation \\
\hline Three neurosurgeons & 1.74 & National average \\
Two neuroanaesthetists & 1.80 & National average \\
Two neuroradiologists & 1.80 & Estimate \\
One neuropathologist & 1.78 & National average \\
Five neurologists & 1.65 & National average \\
One neurcphysiologist & 1.38 & National average \\
\hline
\end{tabular}

* Source: Anonymous. Medical Staffing 1979. Health Trends 1980;12:52.

The following major items of equipment are required for a department of neuroradiology capable of providing the information necessary for the management of patients: general room $(£ 44000)$; skull room ( $£ 68000)$; angiography room $(£ 88000)$; tomography and ventriculography room ( $£ 300000)$; myelography room $(£ 193000)$; and CT scanner $(£ 250000)$. Jonsson and Marke, in their economic evaluation of the cost in Sweden of CT scanning, state that 1500 angiograms and 750 air encephalograms can be performed in their respective diagnostic suites each year. ${ }^{1}$ These figures, which are perfectly feasible, are never attained in practice, as there are more than a sufficient number of departments to meet the clinical demands-for instance, in the Southeast Thames RHA (pop $3.6 \mathrm{~m}$ ) before the introduction of CT scanning about 3000 angiograms and 900 air encephalograms were done annually distributed between five departments. The introduction of CT scanning has probably reduced the number of angiograms by half to 1500 annually and air studies by $90 \%$ to 90 annually. Clearly, on economic grounds it would be hard to justify more than two departments for the South-east Thames RHA.

\section{ASSESSING THE COST}

It is relatively simple to price each resource used by the specialist service. However informative this may seem, it does not show how efficiently the money is used. To answer this question the expenditure must be divided into variable, semivariable, and fixed elements. These divisions will reflect the sensitivity of the cost to the number of patients treated. The costs of specialist equipment, the specialist team, and hospital buildings are fixed. The materials used for radiology and the medication in the treatment are variable because they are directly proportional to the number of patients treated. Because the fixed cost must be divided between the cases treated, the greater the number of patients the less the cost per case, until the level is reached where the equipment or team is fully used. Fig 1 is an example of this principle applied to the cost of CT scanning ${ }^{2}$ and it shows that expensive resources should be fully used.

These concepts can be extended to assess the total cost of a regional service and the cost of treatment for each case. Table II is a set of estimates for the neurosurgical and neurology units serving a population of about $1.8 \mathrm{~m}$. It shows the method used to estimate each figure and an assessment of its sensitivity to the work load (fixed, semifixed, 


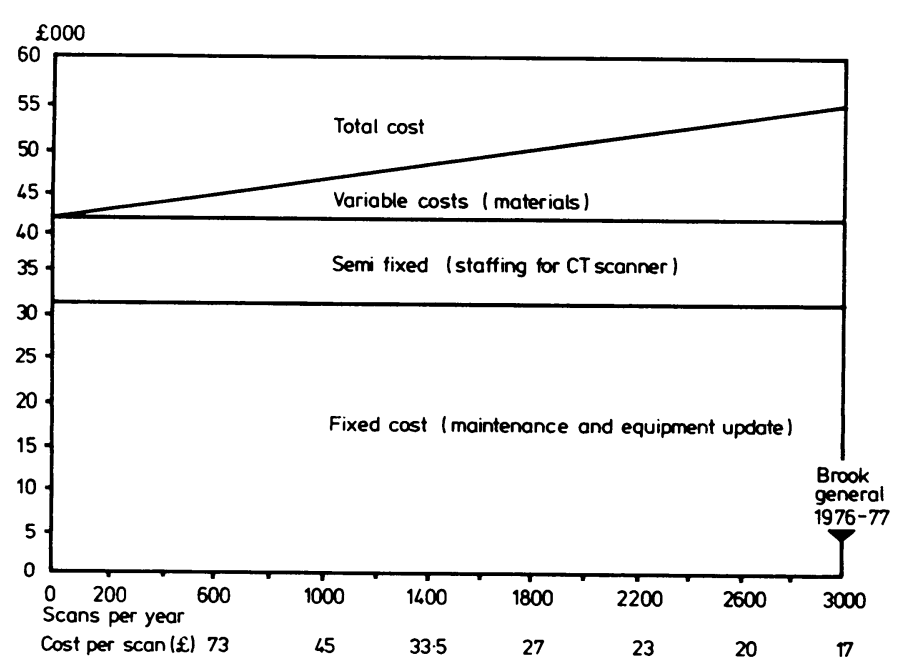

FIG 1-Annual costs of operating an EMI brain scanner.

or variable). There are grey areas, and not everyone will agree with this classification. It is, however, the principle and the magnitude of the fixed costs that require emphasis. Fig 2 summarises the data from table II. While the number of patients treated increases from one to 2200 the total cost of the service rises by only $13 \%$. Fig 2 also shows how the cost of treating each patient increases as the number falls. Neurology consultations and outpatient attendances at peripheral hospitals are included in the assessment of cost. Most patients requiring special investigation are admitted to the main unit. So for the purpose of illustration we divided the total costs by the number of inpatients to derive the figures. Clearly, larger units are more economical than

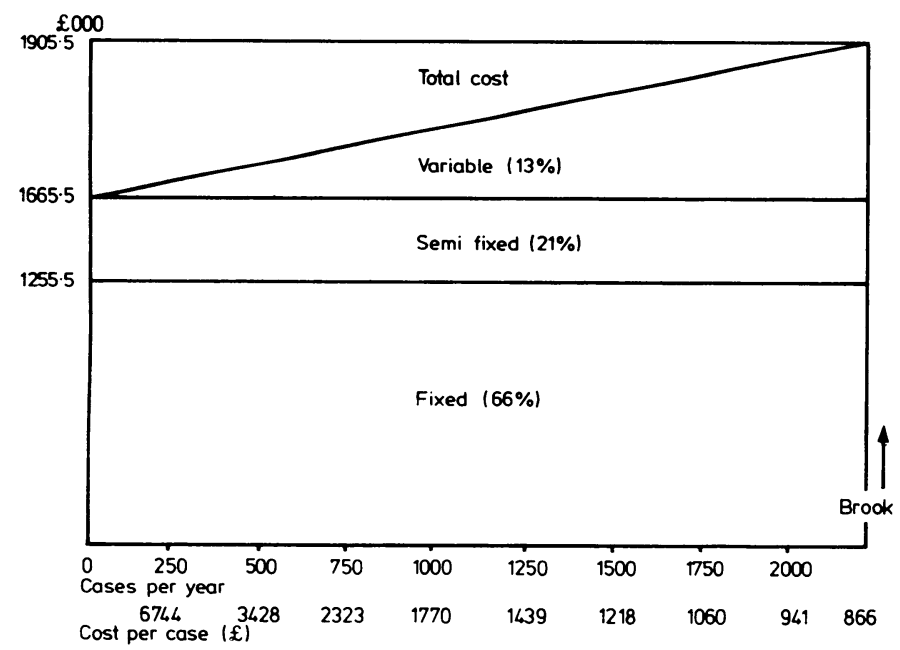

FIG 2-Annual cost of running services in neurology and neurosurgery.

TABLE II-Estimated annual running costs of the regional neurological and neurosurgical units at Brook Hospital (1980)

\begin{tabular}{|c|c|c|c|}
\hline & $£(000)$ & Status & Method of estimation \\
\hline Staff & 700 & Fixed & Pay roll \\
\hline $\begin{array}{l}\text { Special equipment } \\
\text { Buildings }\end{array}$ & 250 & Fixed & $20 \%$ capital value \\
\hline Buildings & & Fixed & $\begin{array}{l}\text { Based on potential for alternative } \\
\text { use }\end{array}$ \\
\hline $\begin{array}{l}\text { Administration } \\
\text { Laboratory }\end{array}$ & $55 \cdot 5$ & $\begin{array}{c}\text { Fixed } \\
\text { Semi }\end{array}$ & $\begin{array}{l}(3 \% \text { of total }) \\
\text { Existing studies }\end{array}$ \\
\hline Hotel & 310 & Semi & $\begin{array}{l}\text { Existing stuades } \\
\text { Existing studies }\end{array}$ \\
\hline Transport & 70 & Variable & $\begin{array}{l}\text { Estimate on journeys and cost per } \\
\text { mile }\end{array}$ \\
\hline $\begin{array}{l}\text { Pharmacy } \\
\text { Materials and drugs }\end{array}$ & $\begin{array}{r}70 \\
100\end{array}$ & $\begin{array}{l}\text { Variable } \\
\text { Variable }\end{array}$ & $\begin{array}{l}\text { Existing studies } \\
\text { Existing studies }\end{array}$ \\
\hline Total & $1905 \cdot 5$ & & \\
\hline
\end{tabular}

smaller units, when judged by the cost of treating each case. Alternatively, the cost of treating patients in small units may be contained to some extent by restricting resources and accepting a lower standard of investigation and treatment.

\section{Discussion}

This analysis has enabled us to describe an "ideal" unit assessed on a cost-effective basis. When an existing unit is compared with the ideal, areas of underprovision and overprovision will be identified. This information should show how to redistribute resources to ensure increased efficiency. Thus in a period of financial restriction priorities can be easily identified. Effective action should reduce the effect of cash limits on patient services. But how do the savings obtained by the better use of resources compare with those made by imposing cash limits on the marginal costs, and what are the implications for patient care? Fig 2 shows that the fixed cost of our specialist services accounts for about $87 \%$ of the total. Many of the elements that make up the fixed cost are indivisible; furthermore, these elements determine the other resources required for efficiency. When the major indivisible elements are cheap in relation to the total cost of the service then duplication is easily justified. There is no great problem when equipment for diagnosis and treatment is simple and the knowledge required is within the compass of many people. But circumstances have changed. Equipment is now expensive and the compendium of medical knowledge has made considerable specialisation necessary to ensure the best results. Any reorganisation of the service that increases the use of expensive resources has a large potential for real savings. Changes in the distribution and organisation of resources would make the use of the remaining spare capacity possible. But to achieve this reduction in the fixed cost certain departments must be favoured and built up at the expense of others. All patients would be treated in these units.

The functional budgeting system, as presented to us, proposes a reduction of the variable costs where small changes in expenditure have the greatest effect on individual patient care. In any event the cash savings possible are small, in our case a fraction of $13 \%$. Those doctors who favour a budget arrangement do so, in our view, because the system seems to give them greater freedom to run their units. The system fails, however, when strict cash limits are imposed. Recently, as a result, the laundry at a district hospital ran out of cash and was not allowed sufficient funds to supply linen for the operating theatres. The theatre services were curtailed and fewer patients were treated.

\section{POTENTIAL FOR VARIATION}

Rudolf Klein ${ }^{3}$ has drawn attention to the conflict that may arise between the maintenance of a national standard of health care and the effects of the devolution of choice to the forthcoming district health authorities. When doctors are given budgets for the service that they provide, the potential for even greater variation becomes possible. Those of us who work in a regional unit have been aware of this general problem and have always advocated separate and clearly defined funding for specialist regional services. The present arrangement that divides financial responsibility for a regional service between the region, area, and district makes it difficult-or dare we say impossible-to make the best use of public funds. There is no method for transferring funds from one area of administration to another and important options remain closed. Further subdivision in the specialty by the creation of budget holders will accentuate this problem.

Doctors should use their knowledge of what happens to patients to advise administrators on methods of making the best use of resources. To do this doctors require some understanding of how their decisions affect real costs. It does not mean that to 


\section{Armed Forces doctors' pay}

The Review Body on Armed Forces Pay has recommended an average increase of about $7 \%$ for Service medical officers. The recommendations are published in the Review Body's Supplement to Tenth Report (Cmnd 8322).

The remuneration of Service doctors is based on the average level of earnings of general medical practitioners. In its evidence the BMA said that failure to take income from other sources into account and to ignore the fact that the average would be depressed by those who did not work full time widened the differences in pay between Service medical officers and general medical practitioners and meant that earnings comparisons were not being properly applied. In its 1981 report the Review Body has taken into account the full range of potential income obtained by the general medical practitioner in respect of NHS patients.

The Review Body has, however, based its recommendations on the actual levels of remuneration of general medical practitioners that have been implemented as a result of the Government's decision to reduce the recommendations of the Doctors' and Dentists' Review Body to $6 \%$, and not on levels that might have applied had circumstances been different.

Various payments for out-of-hours responsibilities are made to NHS doctors and the Review Body says that it is not possible to distinguish precisely between the element that represents payment for work actually undertaken in unsocial hours and that designed to compensate for the commitment to undertake such work. "As was the case last year, we have applied our judgment in making an appropriate adjustment to comparator earnings for this purpose."

The new scales (including the $\mathrm{X}$ factor, a payment that recognises the exigences of Service life) are backdated to 1 April, and range from $£ 4750$ for a cadet on appointment to $£ 22450$ for a brigadier (or equivalent ranks). A preregistration Service doctor will receive $£ 8687$, and on appointment a captain's salary will be $£ 13629$, a major's $£ 14$ 826, a lieutenant-colonel's $£ 18232$, and a colonel's $£ 20688$. After eight years in post a colonel will receive $£ 22028$.

The Review Body has recommended increased payments for consultants but not for specialists or senior specialists-"the re- muneration of Service doctors at these levels compare well with those of equivalent status in the NHS." A consultant will now receive $£ 1700$ a year on appointment, $£ 2025$ after five years, and $£ 2550$ after 10 years.

An allowance of $£ 600$ a year has been recommended for GP trainers on manning grounds. The Review Body says in its report "We are concerned that the Services appear to be having some difficulty in attracting volunteers to undertake responsibilities for training postgraduates in general practice, and acknowledge that comparable levels of vocational training in this respect will have to be offered if the armed Forces are to attract sufficient recruits of the right standard."

On manning in general the Review Body says: "It will take some time to make good the serious shortfalls that occurred during the period when pay in the armed Forces was not kept fully up to date, and when many of the more experienced Service doctors ... were leaving to take up more lucrative posts elsewhere. A lasting improvement can be achieved only through a combination of better recruitment and retention."

The Review Body has estimated the costs of the recommendations to be:

$\begin{array}{lc}\text { Military salary (all Services) } & £ \mathrm{~m} \\ \text { Brigadier } & 0.044 \\ \text { Captain to colonel } & 1.595 \\ \text { Preregistration medical } & \\ \text { practitioners } & 0.033 \\ \text { Medical and dental cadets } & 0.062 \\ \text { Medical and dental additional pay } & 0.065 \\ \text { (all Services) } & 1.799\end{array}$

Medical advice and management-continued from page 453

consult the relevant specialty division, provided other interests are kept informed Similarly it should be possible, on appropriate occasions, for the health board to obtain advice direct from a specialty division, although the outcome should be reported to the area medical committee.

The guiding principle should be that the area medical committee is informed of all medical advice relating to area management, though it need not always be actively involved. It is particularly desirable that the area medical committee should be aware of questions jointly affecting general practitioner and hospital services. It will be for the area medical committee to decide whether a matter raised by the health board should be referred to the subcommittees or even direct to peripheral units for opinions, but the committee must have the confidence of the profession and, having such confidence, be prepared to take decisions when necessary without referral.

\section{Conclusion}

In addition to their care of individual patients, doctors share a broader role in the organisation and management of health care, which is part of their overall professional responsibility. The provisions for medical advice and management put forward in this paper are intended to make it easier for doctors to fulfil this role effectively. Proposals are made to simplify the medical advisory system by concentrating it on area medical committees and medical staff committees related to area and unit management respectively.

To enable the medical profession to develop an incisive role in the management of the service, doctors must be prepared to give their representatives sufficient authority to state the medical view without necessarily having to resort to prior consultation on every issue. This will depend on confident intraprofessional relationships, sustained by good communications and motivated by a determination to ensure that the expert knowledge and experience of doctors is actively brought into management. There is a particular opportunity for community medicine to develop a closer partnership with the clinical specialties and undertake a more positive role in management.

An essential feature of the revised advisory system is that it should be adaptable in the light of local conditions. As the system evolves, a substantial degree of flexibility will be required so that, within a consistent broad approach to structure, variations in local needs and preferences can be accommodated both now and in the future.

Talking Point-continued from page 451

contribute effectively each doctor should have an annual budget. In any event, most doctors have no direct control over the demands made on them and therefore their expenditure.

Some of our assumptions may be challenged. It may be argued that certain fixed costs are too high because the specialist equipment may be used for other purposes and this itself would justify duplication. Others will argue that specialist staff can work effectively at several hospitals. But can such arrangements really provide a first-class, comprehensive, 24-hour service? Inevitably, there will be special circumstances, such as the needs of training undergraduates and postgraduate training, difficulties of access in sparsely populated areas, and so on, many of which will justify extra expense. Our method would establish the real financial cost of the various arrangements-a prerequisite for rational discussion and efficient planning. The clinical advant- ages of different arrangements can be compared and directly related to costs. Facts of this kind would enable doctors, administrators, and accountants to work in partnership and identify ways of improving the use of available resources.

\section{References}

1 Jonsson E, Marke L-A. CAT scanners. The Swedish experience. Health Care Management Review 1977;2:37-53.

2 Bartlett JR, Neil-Dwyer G, Banham JMM, Cruickshank DG. Evaluating cost-effectiveness of diagnostic equipment: the brain scanner case. $\mathrm{Br}$ Med F 1978;ii:815-20.

${ }^{3}$ Klein R. The strategy behind the Jenkin non-strategy. $\mathrm{Br} \mathrm{Med} \mathcal{F} 1981$; 282:1089-91.

(Accepted 17 fune 1981) 